Research Article

\title{
Stress-Strain Calculation Method of Composite Lining considering the Creep Characteristics of Tunnel Surrounding Rock
}

\author{
Shuancheng Gu, ${ }^{1}$ Hengwei He ${ }^{D},{ }^{1}$ and Rongbin Huang ${ }^{2}$ \\ ${ }^{1}$ School of Architecture and Civil Engineering, Xi'an University of Science and Technology, Xi'an 710054, China \\ ${ }^{2}$ Post-Doctoral Mobile Station of Geological Resources and Geological Engineering, Xi'an University of Science and Technology, \\ Xi'an 710054, China
}

Correspondence should be addressed to Hengwei He; 416082172@qq.com

Received 23 July 2021; Accepted 5 October 2021; Published 27 October 2021

Academic Editor: Nicola Baldo

Copyright (c) 2021 Shuancheng Gu et al. This is an open access article distributed under the Creative Commons Attribution License, which permits unrestricted use, distribution, and reproduction in any medium, provided the original work is properly cited.

\begin{abstract}
Tunnels are generally designed for a sustained usage of 80 to 100 years, during which the safety of tunnel structures must be guaranteed. A common supporting form utilized in contemporary tunnel engineering is composite lining. To derive applicable parameters of the supporting form and therefore ensure the long-term safety of the tunnel structure, it is imperative to determine the extra acting force exerted onto the composite lining by the creep of the rock surrounding the tunnel and to calculate the stressstrain characteristics of composite lining. In the current study, this paper proposes an approach termed surrounding reinforcement, which is based on the homogenization method. Specifically, this paper defined the bolt force as the internal force of the surrounding rock, analyzed their viscoelastic-plastic properties using the unified strength theory, and derived an equation for calculating the stress-strain relationship of the composite lining. To further validate the method in tunnel structures, this paper applied the derived equation to a representative instance. The results of this paper show that the initial support force has also increased during the creep process of the surrounding rock, indicating that engineers should pay close attention to the coordination between the strength of initial support and the secondary lining and thus ensure an optimal distribution of the pressure from the surrounding rock when designing composite lining tunnel within weak strata. This paper proposes that the initial support not only would guarantee the tunnel safety during the construction stage but also could cooperate with the secondary lining to brace the stress caused by the creep, ensuring that the supporting structure stays stable across the whole period of tunnel operation. This paper provides an alternative to previous methods that is more comprehensive, with simpler calculations, and more applicable to the composite lining supporting design within weak strata.
\end{abstract}

\section{Introduction}

As a permanent underground building, tunnels need to ensure the stability of surrounding rock during excavation and need to be able to resist additional forces caused by the long-term creep of the surrounding rock during the tunnel operation [1]. Composite lining structure is the most common form of support in present-day tunnel engineering. Without feasible designing parameters for the secondary lining $[2,3]$, weak strata that have already shown conspicuous creep characteristics will eventually fail due to the excessive deformation pressure [4-8]. As shown in Figure 1, common forms of failed designs include tunnel roof subsidence, tunnel lining destruction, tunnel lateral wall destruction, and the destruction of tunnel support steel arch. Therefore, it is an urgent problem to analyze the stress characteristics of composite lining under the creep condition of the surrounding rock from the mechanical point of view and design the secondary lining reasonably [9].

At present, the secondary lining support mechanism considering the creep is mainly studied by means of numerical simulation [10-12], theoretical analysis, and field 

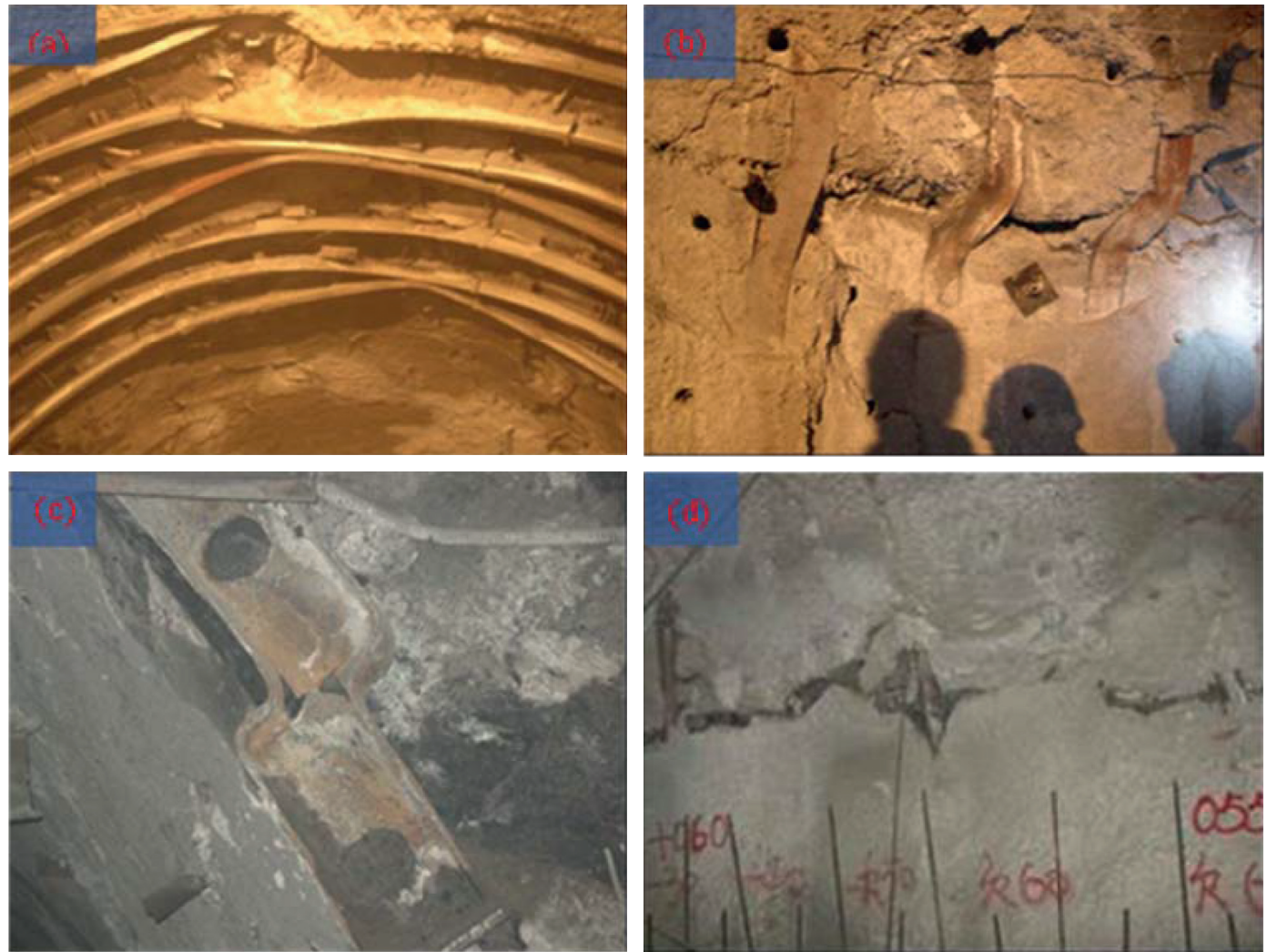

Figure 1: Different forms of tunnel damage: (a) the tunnel support arch being twisted; (b) tunnel lining destruction; (c) tunnel lateral wall destruction; and (d) tunnel lateral wall dehiscence.

data feedback [13]. Xu et al. [14], combined with the uniaxial compression creep test, proposed a numerical method based on the particle discrete element method to describe the typical creep behavior of phyllite. The failure process of the secondary tunnel lining in the phyllite stratum was evaluated by the numerical model method. The results showed that the failure process of the secondary lining was gradual, with four different stages. Huang et al. [15], based on the concept of disturbance state, proposed a new creep constitutive model for soft rocks. It played an essential role in the study of timedependent damage mechanisms governing the deformation behavior of surrounding rocks. Wu et al. [16] divided the whole deformation of lining into two parts for processing: the deformation of highly elements and that of the segmental lining. The viscoelastic analytical solutions of the lining pressure and tunnel displacement at the two deformation stages were deduced respectively. Paraskevopoulou and Diederichs [17], based on mechanical analysis, proposed a convergence-constraint method considering the time effect. Through the above method, the trend of the tunnel lining stress over time could be predicted. Xu et al. [18] investigated the failure process of the secondary lining using the similarity model test and the particle-discrete-element numerical approach. The results showed that the results of the similar model test and numerical simulation were consistent in the order of crack occurring and the final failure pattern. Guan et al. [19], based on the classic Burger-MC rheological model, proposed a Burger-deterioration rheological model composed of a Kelvin unit, a Maxwell unit, and a deteriorating MC unit in series. It could be used to explain the mechanical problems for the delayed deformation after the tunnel was put into use. Wang et al. [20] proposed a highefficiency and high-precision segmented optimization method. The authors aimed to optimize the minimum reserved deformation layer thickness and to evaluate the optimization by the plastic strain of the secondary lining after 100 years of creep occurrence in the surrounding rock. $\mathrm{Chu}$ et al. [21] deduced the expressions of the lining resistance, the lining displacement, and the displacement of surrounding rock in the context of the rheological properties of the surrounding rock. The method for determining the timing was studied in depth, and the values obtained from actual measurements were compared to the theoretical values of the surrounding rock vault subsidence to verify the theoretical accuracy. Wang et al. [22] used the finite element program ANSYS to establish a calculation model and analyzed the force law of the composite lining under different supporting times and different stiffness conditions for the secondary lining. The authors proposed that when designing the composite lining, the initial support should bear all basic loads, while the secondary lining should serve as a safety reserve, and consequently the primary support and the secondary lining could share their specific loads. Cristescu et al. [23] believed that the rock followed the law of nonNewtonian fluid and introduced a nonlinear creep model to analyze the tunnel creep law. Subsequently, they investigated 
the influence of the surrounding rock creep on the force deformation of the lining based on this model.

Although previous studies described above have done substantial research on the force of the composite lining in the creep process of tunnel surrounding rock, there are several limitations:

(1) At present, there is no systematic theoretical understanding of the load transfer law of tunnel lining structure that considers creep action of tunnel surrounding rock, which leads to the lack of a reliable theoretical basis for composite lining design under soft rock conditions.

(2) There is an insufficient study on the rationality of the initial support and secondary support load distribution in the creep process of the tunnel surrounding rock.

To address these limitations, the research ideas of this article are as follows.

Based on the unified strength theory [24-27], the bolt supporting force is regarded as an internal force applied to the surrounding reinforcement, and its mechanical model is established to derive the expression of the tunnel stress and deformation under the composite lining effect. The generalized Kelvin model is used to analyze the creep characteristics of the surrounding rock [28-31], and the law of stress law of the initial support and secondary lining in the creep process of the surrounding rock is obtained. A more reasonable design concept of composite lining is proposed to ensure the stability of the supporting structure and the surrounding rock during the tunnel operation.

\section{Establishment of the Analytical Model}

It is assumed that the radius of the circular tunnel is $r_{0}$, in situ stress is $P$, the supporting force applied by lining is $P_{i}$, the supporting force applied by bolt is $P_{a}$, and the radius of the plastic zone is $r_{p}$. These $P_{i}$ include shotcrete, steel arch, and other supporting forces $P_{s}$ provided by the initial support and forces $P_{c}$ provided by the secondary lining. The bolt and the rock and soil in its anchorage range constitute the reinforcement body of the surrounding rock. The elasticplastic stress of the tunnel should be solved as the plane strain problem. The basic assumptions of the mechanical model are listed as follows: (1) the tunnel section is equivalent to a circular one with infinite length. (2) The original rock stress $P$ is hydrostatic pressure, that is, the lateral pressure coefficient is 1 [32]. (3) The surrounding rock is homogeneous, isotropic, and incompressible material. (4) The surrounding rock reinforcement body is a homogeneous medium. The supporting force of bolt in the surrounding rock reinforcement body is uniformly loaded, and the radius of action is $r_{m}$. The stress changes linearly with the depth of the surrounding rock. (5) The influence of creep of the supporting system on surrounding rocks has been ignored. (6) Compressive stress is defined as negative and tensile stress as positive. The calculation model is shown in Figure 2.

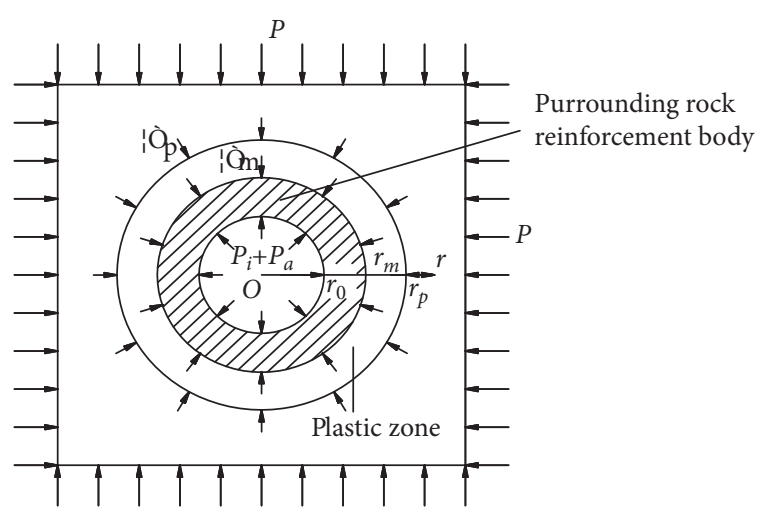

Figure 2: Mechanical calculation model.

\section{Viscoelastic-Plastic Analysis of Tunnel Surrounding Rock}

3.1. Creep Analysis in Elastic Zone. The generalized Kelvin model is widely used in rock mass engineering because it can describe the elastic hysteresis of rock mass and reflect instantaneous deformation characteristics [33-38]. Considering the time effect of stress redistribution in the plastic zone during its formation, this paper analyzed the creep characteristics of rock by using the generalized Kelvin model $[39,40]$. The constitutive model of the generalized Kelvin model is

$$
\left.\begin{array}{l}
\left(1+\frac{\eta_{2}}{G_{1}+G_{2}} D\right) S_{i j}=\left(\frac{G_{1} G_{2}}{G_{1}+G_{2}}+\frac{\eta_{2} G_{1}}{G_{1}+G_{2}} D\right) e_{i j} \\
\sigma_{m}=3 K \varepsilon_{m}
\end{array}\right\} .
$$

In equation (1): $G_{1}, G_{2}, \eta_{2}$ are parameters for the generalized Kelvin model; $D$ is a time-dependent differential operator, $D=\partial / \partial t ; S_{i j}$ is the stress tensor; $e_{i j}$ is a deviatoric tensor of strain, $i, j=x, y, z$ ( $x$ and $y$ represent the horizontal and vertical directions in the plane coordinate system of Figure 2 and $z$ represents the direction along the tunnel); $\bar{\varepsilon}$ represents mean strain; and $\bar{\sigma}$ represents mean stresses.

In the viscoelastic region, for a point of radius $r=\beta r_{p}(t), \beta$ is an arbitrary positive constant. The stress state only varies with the radius $r_{p}(t)$ of the plastic region, but not with time. According to the elastic solution of the plane symmetry problem, equation (1) is deformed into

$$
\begin{aligned}
& \sigma_{r}+P=2 G_{\infty} \varepsilon_{r}+2 \eta_{\mathrm{rel}} G_{\infty} \frac{\mathrm{d} \varepsilon_{r}}{\mathrm{~d} t}, \\
& \sigma_{\theta}+P=2 G_{\infty} \varepsilon_{\theta}+2 \eta_{\mathrm{rel}} G_{\infty} \frac{\mathrm{d} \varepsilon_{\theta}}{\mathrm{d} t} .
\end{aligned}
$$

In equation (2), $G_{\infty}$ is the long-term shear modulus of surrounding rock, $G_{\infty}=G_{1} G_{2} /\left(G_{1}+G_{2}\right) ; \eta_{\text {rel }}$ is slack time, $\eta_{\text {rel }}=\eta_{2} / G_{2} ; \sigma_{r}$ represents radial stress; $\varepsilon_{r}$ represents radial strain; $\sigma_{\theta}$ represents hoop stress; and $\varepsilon_{\theta}$ represents hoop strain.

Assuming that the volume strain of rock mass is zero during creep, 


$$
\frac{\partial u}{\partial r}+\frac{u}{r}=0
$$

where $u$ represents the radial displacement of surrounding rock.

When $t=0$, there is

$$
u(0)=-\frac{\left(P \sin \varphi_{t}+c_{t} \cot \varphi_{t}\right) r_{p}^{2}(0)}{2 G_{0} r},
$$

where $u(0)$ represents the displacement of surrounding rock when $t=0 ; c_{t}$ is the unified cohesion of surrounding rock in the elastic zone; $\varphi_{t}$ is the unified internal friction angle of surrounding rock in the elastic zone.

Thus, the stress and displacement in the viscoelastic region can be obtained:

$$
\left.\begin{array}{l}
\sigma_{r}^{e}(t)=-P-\frac{M r_{p}^{2}(t)}{2 r^{2}} \\
\sigma_{\theta}^{e}(t)=-P+\frac{M r_{p}^{2}(t)}{2 r^{2}} \\
u_{r}^{e}(t)=-\frac{M r_{p}^{2}(t)}{4 r}\left\{\frac{1}{G_{\infty}}\left(1-e^{-\left(t / \eta_{\mathrm{rel}}\right)}\right)+\frac{1}{G_{0}} e^{-\left(t / \eta_{\mathrm{rel}}\right)}\right\}
\end{array}\right\} .
$$

In equation (5),

$$
M=\sigma_{\theta}-\sigma_{r}=-2\left(P \sin \varphi_{t}+c_{t} \cot \varphi_{t}\right) .
$$

In equations (5) and (6), $\sigma_{r}^{e}(t)$ is the radial stress in the viscoelastic region; $\sigma_{\theta}^{e}(t)$ is the hoop stress in the viscoelastic region; $u_{r}^{e}(t)$ is the radial displacement of the viscoelastic region; and $M$ is the differential value between circumferential stress and radial stress of surrounding rock.

3.2. Creep Analysis in Plastic Zone. To study the load transfer law of supporting structure and surrounding rock more accurately and consider the influence of intermediate principal stress, this paper conducted the elastic-plastic analysis of tunnel surrounding rock by using unified strength theory [41]. Namely,

$$
\frac{\sigma_{r}-\sigma_{\theta}}{2}=-\frac{\sigma_{r}+\sigma_{\theta}}{2} \sin \varphi_{i}+c_{i} \cos \varphi_{i},
$$

where $\varphi_{i}$ is the unified internal friction angle of geotechnical materials under different states, and $c_{i}$ is the unified cohesion of geotechnical materials under different states, where $i=$ $1,2,3$ indicates the state of surrounding rock in elastic zone, fractured zone, and surrounding rock reinforcement body, respectively.

When $i=1$,

$$
\begin{aligned}
\sin \varphi_{1} & =\sin \varphi_{t}=\frac{2(1+b) \sin \varphi}{2+b(1+\sin \varphi)}, \\
c_{1} & =c_{t}=\frac{2(1+b) c \cos \varphi}{2+b(1+\sin \varphi)} \cdot \frac{1}{\cos \varphi_{t}},
\end{aligned}
$$

where $c$ and $\varphi$ are the cohesive force and internal friction angle of surrounding rock, respectively. $b$ is the influence parameter of intermediate principal stress, representing the coefficient of the influence degree of intermediate principal shear stress and normal stress on the corresponding plane on material failure, and the value range is $0 \leq b \leq 1$.

When $i=2$,

$$
\begin{aligned}
\sin \varphi_{2} & =\sin \varphi_{t}^{\prime}=\frac{2(1+b) \sin \varphi^{\prime}}{2+b\left(1+\sin \varphi^{\prime}\right)}, \\
c_{2} & =c_{t}^{\prime}=\frac{2(1+b) c_{0}^{\prime} \cos \varphi^{\prime}}{2+b\left(1+\sin \varphi^{\prime}\right)} \cdot \frac{1}{\cos \varphi_{t}^{\prime}},
\end{aligned}
$$

where $c^{\prime}$ is the cohesion of the rock mass in the loosened area, and $\varphi^{\prime}$ is the internal friction angle of the rock mass in the loosened area.

When $i=3$,

$$
\begin{aligned}
\sin \varphi_{3} & =\sin \varphi_{b}=\frac{2(1+b) \sin \varphi_{b t}}{2+b\left(1+\sin \varphi_{b t}\right)}, \\
c_{3} & =c_{b}=\frac{2(1+b) c_{b t} \cos \varphi_{b t}}{2+b\left(1+\sin \varphi_{b t}\right)} \cdot \frac{1}{\cos \varphi_{b}},
\end{aligned}
$$

where $\varphi_{b t}$ is the cohesion of surrounding rock reinforcement body; $\varphi_{b t}=\varphi^{\prime}$ can be taken; $c_{b t}$ is the internal friction angle of surrounding rock reinforcement body; and

$$
c_{b t}=c^{\prime}+\frac{\tau_{b} A_{s}}{S_{a} S_{b}}
$$

where $\tau_{b}$ is the shear strength of the anchor; $A_{s}$ is the crosssectional area of the anchor; and $S_{a}, S_{b}$ are the row spacing between the anchors.

If the bolt supporting force is regarded as a physical force, the equilibrium equation of the axisymmetric plane strain mechanics model in the surrounding rock reinforcement body is as follows:

$$
\frac{\mathrm{d} \sigma_{r}}{\mathrm{~d} r}+\frac{\sigma_{r}-\sigma_{\theta}}{r}+\frac{1}{r} \cdot \frac{r_{0}}{r} P_{a}=0
$$

According to the boundary bar when $r=r_{0}$, there is $\sigma_{r}=-\left(P_{i}+P_{a}\right)$, obtained by the simultaneous equations (7), (10), and (12). The stress distribution of surrounding rock reinforcement can be 


$$
\left.\left.\begin{array}{l}
\sigma_{r}=-\left(P_{i}+\frac{2 P_{a}}{1+\sin \varphi_{b}}+c_{b} \cot \varphi_{b}\right)\left(\frac{r}{r_{0}}\right)^{2 \sin \varphi_{b} /\left(1-2 \sin \varphi_{b}\right)}+\frac{P_{a} r_{0}\left(1-\sin \varphi_{b}\right)}{r\left(1+\sin \varphi_{b}\right)}+c_{b} \cot \varphi_{b} \\
\sigma_{\theta}=-\left(P_{i}+\frac{2 P_{a}}{1+\sin \varphi_{b}}+c_{b} \cot \varphi_{b}\right) \frac{\left(1+\sin \varphi_{b}\right)}{\left(1-\sin \varphi_{b}\right)}\left(\frac{r}{r_{0}}\right)^{2 \sin \varphi_{b} /\left(1-2 \sin \varphi_{b}\right)}+\frac{P_{a} r_{0}}{r}+c_{b} \cot \varphi_{b}
\end{array}\right\} \quad \begin{array}{c}
\left(r_{0} \leq r \leq r_{m}\right) \\
\end{array}\right\}
$$

The force acting on the bolt in the upper form is

$$
P_{a}=\frac{Q+Q_{1}}{S_{a} S_{b}} \text {. }
$$

where $Q$ is the anchor force caused by the deformation of surrounding rock; $Q_{1}$ is the pretension force of anchor; and the other symbols have the same meaning as before.

Among them,

$$
Q=\frac{u_{r=r_{0}}-u_{r=r_{m}}}{r_{m}-r_{0}} E_{c b} A_{s}
$$

where $E_{c b}$ is the elastic modulus of the bolt and $u_{r=r_{0}}-u_{r=r_{m}}$ are the displacements of the inside and outside ends of the bolt, respectively.

Obtained from equation (11), the stress conditions at the external boundary of surrounding rock reinforcement can be $\sigma_{m}=\left(\sigma_{r}\right)_{r=r_{m}}$. Repeating the above analysis process and using equations (7) and (8), this paper can obtain the stress distribution of surrounding rock in the plastic zone of external reinforcement of surrounding rock:

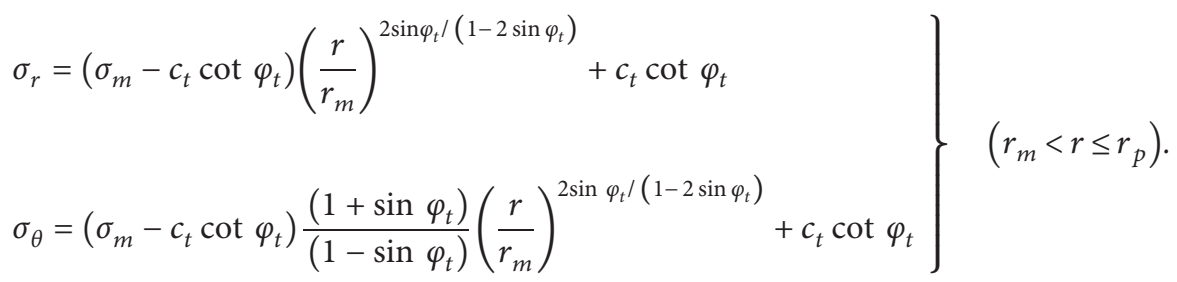

On the elastic-plastic interface, $\left(r=r_{p}\right)$ satisfying

$$
\sigma_{r}+\sigma_{\theta}=-2 P
$$

Then, the radius of the plastic zone is

$$
r_{p}=r_{m}\left[\frac{\left(1-\sin \varphi_{t}\right)\left(c_{t} \cot \varphi_{t}+P\right)}{c_{t} \cot \varphi_{t}-\sigma_{m}}\right]^{\left(1-\sin \varphi_{t}\right) / 2 \sin \varphi_{t}}
$$

Substituting equation (18) into equation (16), obtainable stress on the elastic-plastic boundary is

$$
\left.\begin{array}{l}
\sigma_{r}=-\left(1-\sin \varphi_{t}\right) P+c_{t} \cos \varphi_{t} \\
\sigma_{\theta}=-\left(1+\sin \varphi_{t}\right) P-c_{t} \cos \varphi_{t}
\end{array}\right\} .
$$

Based on the assumption that the volume of the plastic zone is invariant, the radial displacement expression of the plastic zone is as follows:

$$
\begin{aligned}
u_{r} & =\frac{(1+\mu) r_{p}^{2}}{2 r E}\left(P \sin \varphi_{t}+c_{t} \cos \varphi_{t}\right) \\
& =-\frac{M r_{p}^{2}}{4 G r},
\end{aligned}
$$

where $E$ is the elastic modulus of surrounding rock; $G$ is the shear modulus of surrounding rock; and $\mu$ is Poisson's ratio of surrounding rock. The other symbols have the same meaning.
Transforming equation (20) with Laplace transformation, the following equations are obtained:

$$
\tilde{u}_{r}(s)=-\frac{M r_{p}^{2}(t)}{4 s \widetilde{G}(s) r}
$$

Then, the displacement of surrounding rock is obtained by Laplace reversal:

$$
u_{r}(t)=-\frac{M r_{p}^{2}(t)}{4 r}\left\{\frac{1}{G_{\infty}}\left[1-e^{-\left(t / \eta_{\text {rel }}\right)}\right]+\frac{1}{G_{1}} e^{-\left(t / \eta_{r e l}\right)}\right\} \text {. }
$$

The supporting force provided by initial support is

$$
P_{s}(t)=K_{s}\left[u_{r}(t)-u_{0}^{\prime}\right]
$$

where $u_{0}^{\prime}$ is the displacement release of surrounding rock when bolt support is applied considering the spatial effect of tunnel excavation, which can be calculated by $60 \%$ of the elastic displacement of surrounding rock or $20 \%$ to $30 \%$ of the total displacement; $K_{s}$ is the stiffness coefficient of initial support; and

$$
K_{s}=\frac{E_{s} d}{r_{1}^{2}}
$$

where $E_{s}$ is the elastic modulus of shotcrete and $d$ is the thickness of shotcrete. 
The supporting force provided by secondary lining is

$$
\begin{aligned}
P_{c}(t) & =K_{c}\left(u_{b r}\right)_{r=r_{1}} \\
& =K_{c}\left[u_{r 1}(t)-u_{0}\right],
\end{aligned}
$$

where $u_{0}$ is the radial displacement of surrounding rock before secondary lining construction. Assuming that the elastic-plastic deformation of surrounding rock is complete and the creep deformation of lining is not taken into account, the following equation can be obtained at this time:

$$
u_{0}=u_{r=r_{0}}=-\frac{M r_{p}^{2}}{4 G r_{0}}
$$

where $K_{c}$ is the stiffness coefficient of lining, and

$$
K_{c}=\frac{2 G_{c}\left(r_{1}^{2}-r_{2}^{2}\right)}{r_{1}\left[\left(1-2 \mu_{c}\right) r_{1}^{2}+r_{2}^{2}\right]},
$$

where $G_{c}$ is the shear modulus of secondary lining; $\mu_{c}$ is Poisson's ratio of secondary lining; and $r_{2}, r_{1}$ are the internal and external radius of the secondary lining.

Then, the stress distribution of surrounding rock reinforcement is

$$
\left.\begin{array}{l}
\sigma_{r}=-\left(P_{c}(t)+P_{s}(t)+\frac{2 P_{a}(t)}{1+\sin \varphi_{b}}+c_{b} \cot \varphi_{b}\right)\left(\frac{r}{r_{0}}\right)^{2 \sin \varphi_{b} /\left(1-2 \sin \varphi_{b}\right)}+\frac{P_{a}(t) r_{0}\left(1-\sin \varphi_{b}\right)}{r\left(1+\sin \varphi_{b}\right)}+c_{b} \cot \varphi_{b} \\
\sigma_{\theta}=-\left(P_{c}(t)+P_{s}(t)+\frac{2 P_{a}(t)}{1+\sin \varphi_{b}}+c_{b} \cot \varphi_{b}\right) \frac{\left(1+\sin \varphi_{b}\right)}{\left(1-\sin \varphi_{b}\right)}\left(\frac{r}{r_{0}}\right)^{2 \sin \varphi_{b} /\left(1-2 \sin \varphi_{b}\right)}+\frac{P_{a}(t) r_{0}}{r}+c_{b} \cot \varphi_{b}
\end{array}\right\} .
$$

From equation (28), the force at the interface between reinforcement body and plastic zone $\left(r=r_{m}\right)$ can be obtained at $t$ time, and the radius expression of the plastic zone can be obtained:

$$
r_{p}(t)=r_{m}\left[\frac{\left(1-\sin \varphi_{t}\right)\left(c_{t} \cot \varphi_{t}+P\right)}{c_{t} \cot \varphi_{t}-\sigma_{r m}(t)}\right]^{\left(1-\sin \varphi_{b}\right) / 2 \sin \varphi_{t}} .
$$

\section{Stress Form Analysis of Composite Lining}

When using composite lining for tunnel support, it is generally required that the initial support should fully ensure the stability of surrounding rock during tunnel excavation, while the secondary lining mainly bears the additional stress caused by rock creep during service and provides appropriate safety reserve [42]. However, during the operation of the tunnel, the maximum radius of the surrounding rock fractured zone should not exceed the scope of the surrounding rock reinforcement body, to avoid the instability of the tunnel caused by the failure of bolts, which makes the weight load of the surrounding rock in the fractured zone attached to the secondary lining. Secondly, the initial support and the secondary lining during the creep process of the surrounding rock should be guaranteed to bear the additional stress of the surrounding rock creep, to ensure the surrounding rock and supporting structure of the tunnel during the operation are stable.

4.1. Stress Calculation of Support Structure. Assuming that the design life of the tunnel is $T$, substituting $t=T$ into the theoretical deduction mentioned above, the radius of the plastic zone $r_{p}(T)$ and displacement $u_{r_{0}}(T)$ of surrounding rock and radial displacement $u_{r_{m}}(T)$ of the external boundary of surrounding rock reinforcement during operation can be calculated. Then, the stress of the anchor bolt can be solved:

$$
P_{a}(T)=\frac{1}{S_{a} S_{b}}\left\{\frac{u_{r_{0}}(T)-u_{r_{m}}(T)}{r_{m}-r_{0}} E_{c b} A_{s}+Q_{1}\right\} .
$$

The force acting on shotcrete is as follows:

$$
P_{s}(T)=K_{s}\left[u_{r_{0}}(T)-u_{0}^{\prime}\right] \text {. }
$$

The force acting on the secondary lining is as follows:

$$
P_{c}(T)=K_{c}\left[u_{r 1}(T)-u_{0}\right] \text {. }
$$

4.2. Stability Checking Calculation of Supporting System. Under the creep action of surrounding rock during tunnel operation, the supporting force of the bolt gradually increases to a certain value. Suppose the supporting force is greater than the design value of the supporting strength of the bolt. In that case, the supportive effect will be lost due to the tension failure of the bolt and the instability and collapse of the surrounding rock in the fractured area. At this time, the secondary lining bears the additional force produced by rock creep and needs to resist the self-weight force of collapsed rock mass. It has adverse effects on tunnel stability. Therefore, the creep effect of surrounding rock should be considered, and the strength of the tunnel support structure should be checked.

4.2.1. Stability Check of Bolt Support System considering Creep of Surrounding Rock. To ensure the stability of the bolt support system [43], it should satisfy 


$$
f(T)=\frac{P_{a}(T) S_{a} S_{b}}{A_{s}}<f_{s d},
$$

where $f(T)$ is the tension stress of a single bolt and $f_{s d}$ is the design value of the tension strength of the bolt.

If the stress of the bolt does not satisfy equation (33) after checking calculation, the supporting effect of bolt should be strengthened or the strength of secondary lining should be increased to share the supporting force of the bolt.

4.2.2. Calculation of Lining Ultimate Bearing Capacity. The plastic failure of the inner edge under confining pressure is taken as the calculation condition of the limit supporting force of secondary lining. The inner and outer radius of the lining are $r_{1}$ and $r_{2}$, respectively. $P^{\prime}$ acts on the outer edge of the secondary lining. The elastic stress solution of the secondary lining obtained from Lame's solution is as follows:

$$
\left.\begin{array}{l}
\sigma_{r}^{e}=\frac{r_{2}^{2} r_{1}^{2} P^{\prime}}{\left(r_{2}^{2}-r_{1}^{2}\right)} \cdot \frac{1}{r^{2}}-\frac{r_{2}^{2} P^{\prime}}{r_{2}^{2}-r_{1}^{2}} \\
\sigma_{\theta}^{e}=-\frac{r_{2}^{2} r_{1}^{2} P^{\prime}}{\left(r_{2}^{2}-r_{1}^{2}\right)} \cdot \frac{1}{r^{2}}-\frac{r_{2}^{2} P^{\prime}}{r_{2}^{2}-r_{1}^{2}}
\end{array}\right\},
$$

where $P^{\prime}$ represents the force on the outer edge of the secondary lining.

To obtain the ultimate bearing capacity of lining and make lining just enter the plastic state, that is, $r=r_{1}$ is an elastic-plastic interface at this time, according to the Mohr-Coulomb criterion, it can be concluded that

$$
P_{i \max }=\frac{\left(r_{2}^{2}-r_{1}^{2}\right) c_{c} \cos \varphi_{c}}{r_{2}^{2}\left(1-\sin \varphi_{c}\right)},
$$

where $P_{i \max }$ is the ultimate bearing capacity of secondary lining; $c_{c}$ is the cohesion of secondary lining; $\varphi_{t}$ is the angle of internal friction of secondary lining.

Then, the secondary lining supporting force derived from the theory in this paper should satisfy

$$
P_{i}(T) \leq P_{\max },
$$

where $P_{i}(T)$ represents the maximum force on the secondary lining during the creep process.

Similarly, the ultimate bearing capacity of shotcrete can be obtained as follows:

$$
P_{s \max }=\frac{\left(r_{0}^{2}-r_{2}^{2}\right) c_{s} \cos \varphi_{s}}{r_{0}^{2}\left(1-\sin \varphi_{s}\right)},
$$

where $P_{s \max }$ is the ultimate bearing capacity of shotcrete; $c_{s}$ is the cohesive force of shotcrete; and $\varphi_{s}$ is the internal friction angle of shotcrete.

The shotcrete supporting force should be satisfied:

$$
P_{s}(T) \leq P_{\max },
$$

where $P_{s}(T)$ is the maximum force on shotcrete during the creep process.
Equations (36) and (38) are used to evaluate the stability of lining. If the conditions mentioned above are not satisfied, measures such as increasing lining thickness or increasing lining label should be taken to ensure the stability of tunnel lining in operation.

The stress of composite lining support structure is calculated by equations (30)-(32) and checked by equations (33), (36), and (38). Finally, the stress characteristics under specific engineering geological conditions are determined, which provides a reference for the design of support structure and stability evaluation.

\section{Engineering Example Analysis}

The expressway from Shiyan city in Hubei province to Tianshui city in Gansu province is a horizontal link in the national expressway network design. It is an important component of Shaanxi's expressway network that "connects east and west, connects north and south, covers the whole province, and reaches all neighbors." The Mingyazi tunnel is located in Shaanxi province, which is the only specialty tunnel across the whole line. The length of the right line of the tunnel is $4980 \mathrm{~m}$, and the length of the left line is $4944 \mathrm{~m}$. It belongs to the superlong tunnel and is the control project of Shiyan-Tianshui Expressway construction. The site of the tunnel is shown in Figure 3 [44, 45].

This paper applied the theoretical results of this paper to analyze the force of supporting structure.

The equivalent radius of the tunnel is $r_{0}=7.8 \mathrm{~m}$, the initial amplitude of Earth stress is $P=2.3 \mathrm{MPa}$, and the specific engineering geological parameters are shown in Table 1.

5.1. Force Law of Initial Support. As shown in Figure 4, given that other supporting conditions remain unchanged, the initial support should be designed in accordance with the principle that the joint force can guarantee the safety of the construction stage with the surrounding rock. The diameter of the bolt is calculated to be $18 \mathrm{~mm}$. the spacing between rows is $1.5 \mathrm{~m} \times 1.5 \mathrm{~m}$, and the shotcrete thickness is $160 \mathrm{~mm}$. That is to say, it meets the requirements of the above principles. At this time, the ultimate bearing capacity of shotcrete $P_{s 1}=0.272 \mathrm{MPa}$. With the creep development of surrounding rock, shotcrete stress increases gradually (as shown in Figure 3). When $t=20 d$, the spray $S_{a} \times S_{b}=1.5 \mathrm{~m} \times 1.5 \mathrm{~m}$ concrete has already reached the stress limit, after which the shotcrete will be destabilized and ultimately destroyed, leading to declining stability of surrounding rock reinforcement. This is not conducive to the long-term stability of the tunnel. Therefore, the thickness of shotcrete should be increased. Take $h_{1}=200 \mathrm{~mm}$, and according to the service life of 100 years to calculate and analyze ( $T=100$ years), it is concluded that the maximum force of shotcrete is $0.339 \mathrm{MPa}$, and at this time, the ultimate bearing capacity of concrete is $P_{s 2}=0.367 \mathrm{MPa}$. That is, shotcrete can provide support for the surrounding rock of the tunnel without damage during the whole operation period of the tunnel. 


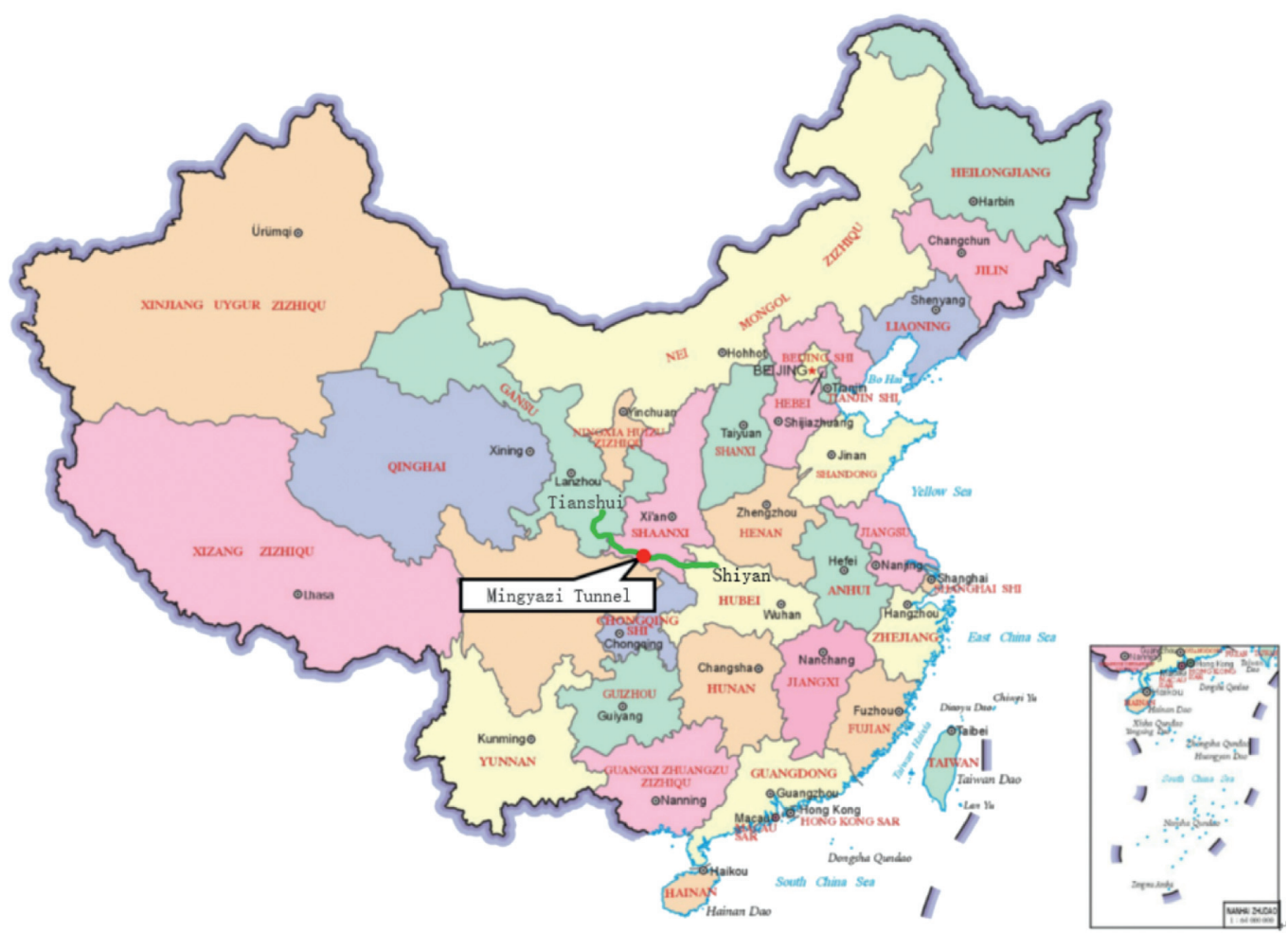

FIgURE 3: The site of the Mingyazi tunnel in china.

TABLE 1: Engineering geology and support parameters.

\begin{tabular}{|c|c|c|c|c|c|c|c|}
\hline \multicolumn{2}{|l|}{ Surrounding rock } & \multicolumn{2}{|l|}{ Bolt } & \multicolumn{2}{|l|}{ Sprayed concrete } & \multicolumn{2}{|l|}{ Secondary lining } \\
\hline Cohesion $(\mathrm{MPa})$ & 0.15 & Diameter $(\mathrm{mm})$ & 18 & Concrete grade & $\mathrm{C} 20$ & Concrete grade & $\mathrm{C} 35$ \\
\hline Angle of internal friction $\left({ }^{\circ}\right)$ & 27 & Cross section area $\left(\mathrm{mm}^{2}\right)$ & 276.6 & Thickness (mm) & 160 & Thickness (mm) & 300 \\
\hline $\begin{array}{l}\text { Instantaneous shear modulus } \\
(\mathrm{GPa})\end{array}$ & 1.10 & $\begin{array}{c}\text { Design value of tension } \\
\text { strength }(\mathrm{MPa})\end{array}$ & 300 & Internal radius $(\mathrm{m})$ & 7.64 & Internal radius $(\mathrm{m})$ & 7.34 \\
\hline Delayed shear modulus (GPa) & 1.34 & Length $(\mathrm{m})$ & 2.1 & Shear modulus (GPa) & 28 & Shear modulus (GPa) & 31 \\
\hline Poisson's ratio & 0.25 & Elastic modulus (GPa) & 200 & Cohesion $(\mathrm{MPa})$ & 2.27 & Cohesion $(\mathrm{MPa})$ & 3.18 \\
\hline Viscosity coefficient $(\mathrm{GPa} \cdot \mathrm{d})$ & 105 & Spacing $(\mathrm{m})$ & 1.5 & $\begin{array}{l}\text { Angle of internal } \\
\text { friction }\left(^{\circ}\right)\end{array}$ & 52.6 & $\begin{array}{l}\text { Angle of internal } \\
\text { friction }\left(^{\circ}\right)\end{array}$ & 54.9 \\
\hline & & Row distance $(\mathrm{m})$ & 1.5 & & & & \\
\hline
\end{tabular}

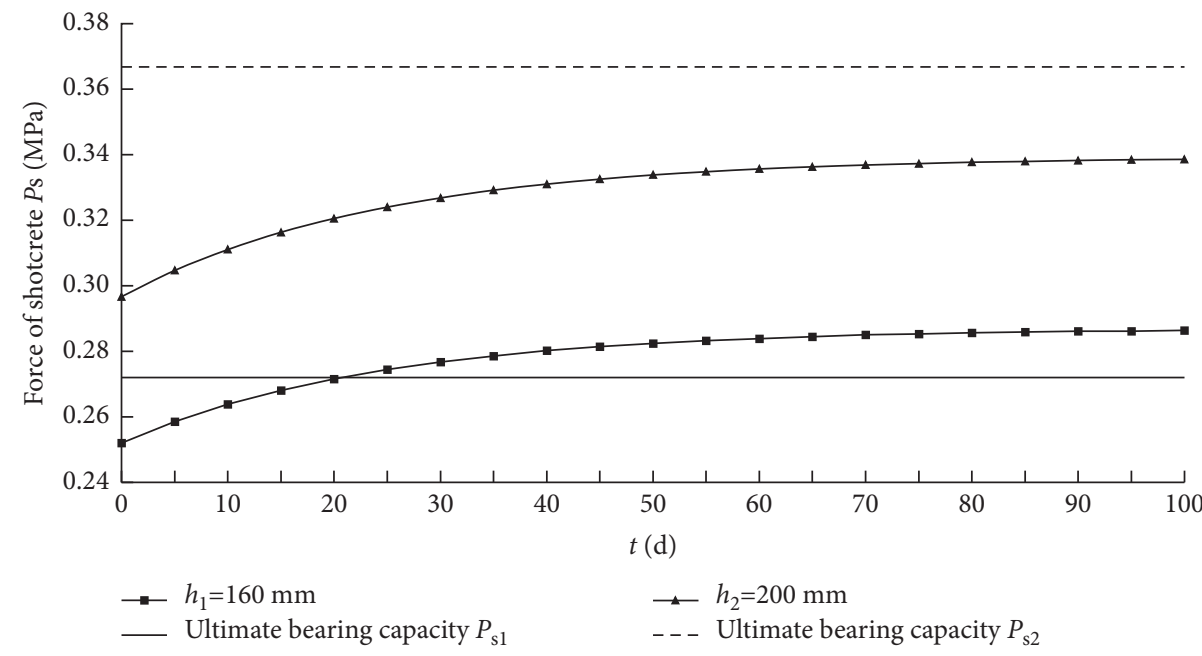

FIgURE 4: Radial force variation of shotcrete with time. 


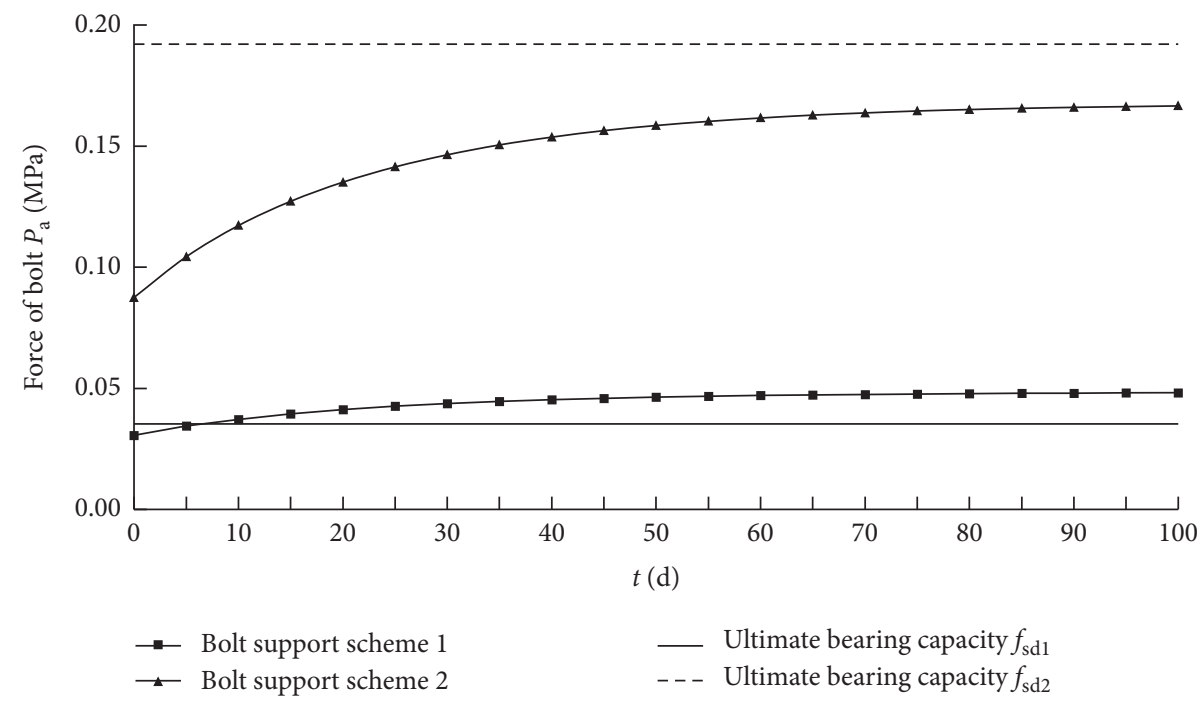

FIGURE 5: Radial force variation of the bolt with time.

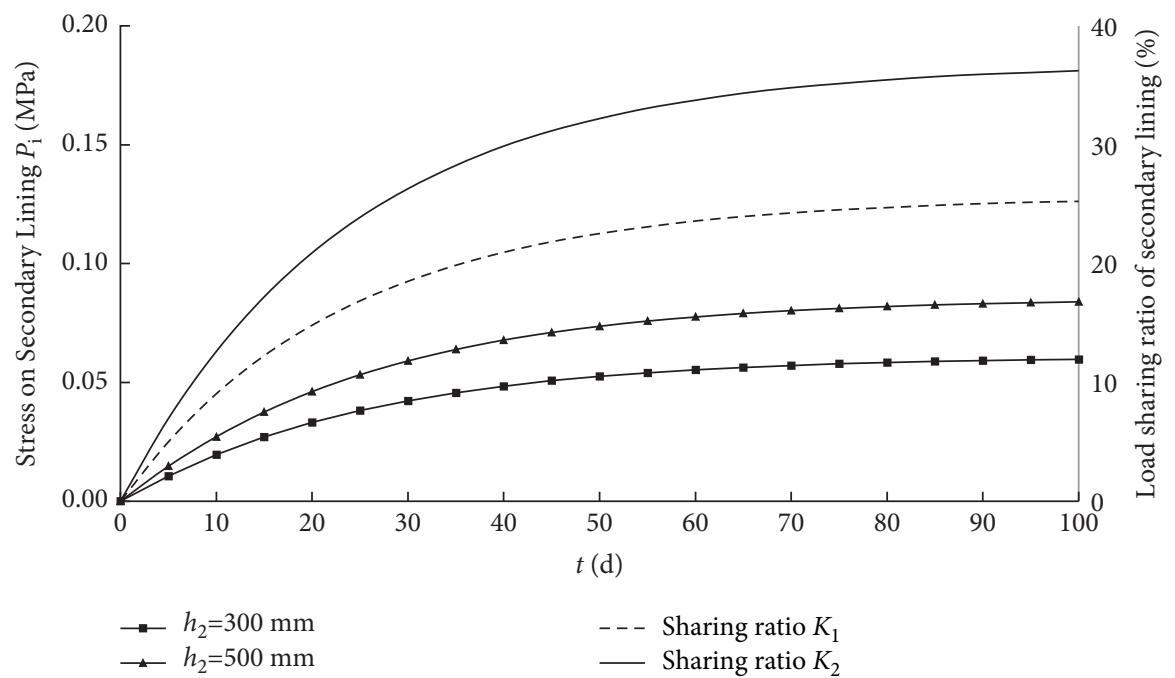

Figure 6: Variation of radial force with time under different thicknesses of the secondary lining.

Figure 5 shows the variation law of bolt radial stress with time under different support conditions. When adopting bolt support scheme 1, bolt parameters take diameter $\varphi 18$, spacing between rows $S_{a} \times S_{b}=1.5 \mathrm{~m} \times 1.5 \mathrm{~m}$ for initial bolt support. Although the stability of surrounding rock can be guaranteed during tunnel excavation, the stress of the anchor gradually increases when the surrounding rock enters the creep process. This eventually leads to the failure of anchor rod when the stress exceeds its ultimate bearing capacity, which has adverse effects on the stability of surrounding rock reinforcement. When adopting bolt support scheme 2 (bolt parameters take diameter $\phi 28$, spacing between rows $S_{a} \times S_{b}=1.0 \mathrm{~m} \times 1.0 \mathrm{~m}$ ) for initial bolt support, the stress level of bolt increases, indicating that the supporting effect of bolt increases. With the creep of surrounding rock, the maximum stress of bolt is $0.168 \mathrm{MPa}$, but the ultimate bearing capacity provided by bolts in this scheme is $f_{s d 2}=0.192 \mathrm{MPa}$. Therefore, during the whole operation period of the tunnel, the anchor bolt can resist the additional stress caused by creep of surrounding rock without fracture failure.

5.2. Stress Law of Secondary Lining. As shown in Figure 6, with the creep of surrounding rock, the radial force of secondary lining increases, but the change rate decreases gradually. Other conditions remain unchanged. When the thickness of the secondary lining increases from $300 \mathrm{~mm}$ to $500 \mathrm{~mm}$, the radial force of the secondary lining increases at the same time. The load-sharing ratio of the secondary lining (the ratio of secondary lining support force to initial support surrounding rock pressure) $K$ increases with the creep of surrounding rock, indicating that the supporting effect of secondary lining increases gradually during the creep process to bear additional stress caused by the creep of 


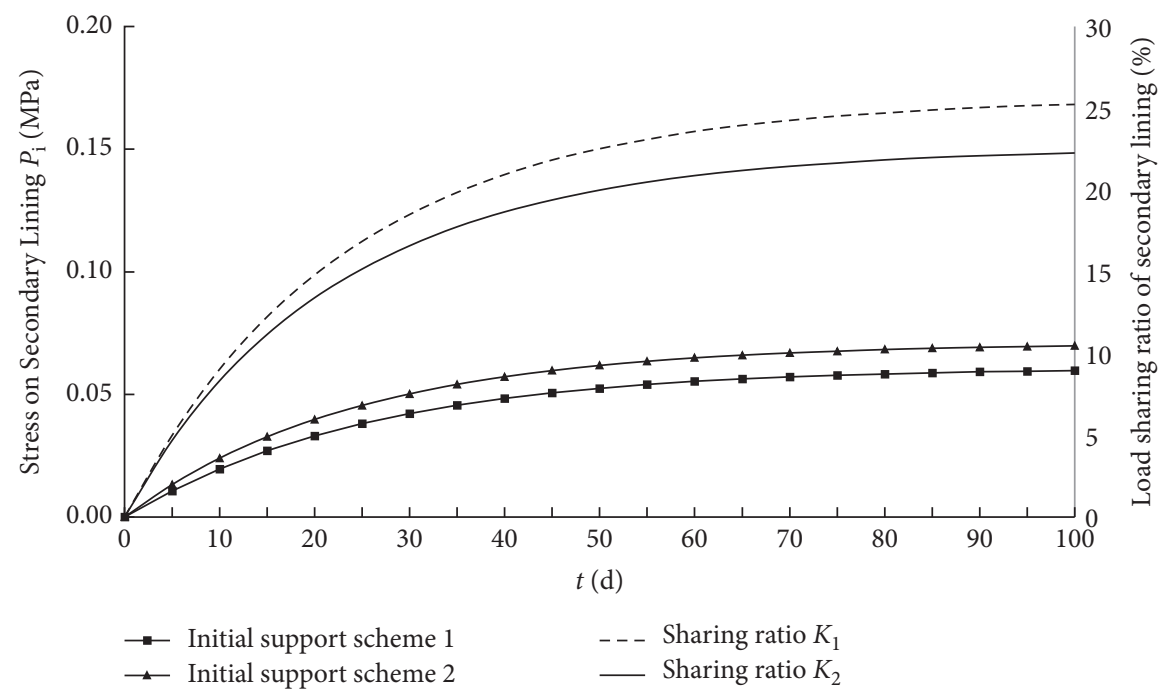

FIGURE 7: Variation of radial force of secondary lining with time under different conditions of primary support.

surrounding rock. The ultimate load-sharing ratio of the two kinds of secondary lining thickness is $25.6 \%$ and $36.8 \%$, indicating that increasing the thickness of secondary lining reduces the proportion of stress in surrounding rock and initial support and makes the stress of surrounding rock concentrate on the secondary lining.

As shown in Figure 7, when the initial support strength is relatively conservative (initial support scheme 1), the stress level and load-sharing ratio of secondary lining decrease during the creep process of surrounding rock. This is because the elastic modulus of surrounding rock reinforcement increases with the increase of initial support strength. Its load-bearing capacity increases with the rise in initial support strength. The process of coordinated deformation of the supporting structure and surrounding rock can share a larger proportion. Additional stress caused by the creep of surrounding rock results in the decrease of the load-sharing ratio of secondary lining [46].

\section{Discussions}

Based on the homogenization method, the concept of surrounding rock plus solid is proposed, and the stress variation law of primary support and secondary lining in the process of surrounding rock creep is obtained. The theoretical model adopted in this paper does not consider the influence of tunnel section shape, lateral pressure coefficient, and other factors on lining stress. The above problems will be further analyzed in the follow-up research.

\section{Conclusions}

(1) Based on the unified strength theory, this paper derived an equation that characterizes the relationship between stress and deformation by performing a viscoelasticplastic analysis on the surrounding rock reinforcement body. In the model of this paper, both the bolt and the soil within its anchorage range are considered as the surrounding rock reinforcement body. The bolt force is regarded as the internal force that acts on the surrounding rock reinforcement body.

(2) The example in this paper analysis reveals that, during the creep process of surrounding rock, the loadsharing ratio of secondary lining gradually increases, whereas its change rate gradually decreases. At the same time, the load-sharing ratio of secondary lining decreases with more initial support, while the opposite happens with more secondary lining support. Therefore, when designing composite lining, attention should be paid to the coordinated allocation of initial support and secondary lining support strength, optimizing their respective supporting role in the creep process of surrounding rock.

(3) This paper proposes that when designing the composite lining in weak strata, the initial support should not only guarantee the tunnel safety during the construction stage but also cooperate with the secondary lining to brace the additional stress caused by the creep, ensuring that the supporting structure stays stable across the whole period of tunnel operation.

\section{Data Availability}

The data used to support the findings of this study are available from the corresponding author upon request.

\section{Conflicts of Interest}

The authors declare that they have no conflicts of interest regarding the publication of this paper.

\section{Acknowledgments}

This work was supported in part by the China Postdoctoral Science Foundation (2019M663936XB) and the Scientific Research Program Funded by Shaanxi Provincial Education Department (19JK0399). 


\section{References}

[1] W. Q. Mu, L. C. Li, D. Z. Chen, S. X. Wang, and F. K. Xiao, "Long-term deformation and control structure of rheological tunnels based on numerical simulation and on-site monitoring," Engineering Failure Analysis, vol. 118, Article ID 104928, 2020

[2] C. H. Bai, Y. G. Xue, D. H. Qiu, Y. Weimin, S. Maoxin, and M. Xinmin, "Real-time updated risk assessment model for the large deformation of the soft rock tunnel," International Journal of Geomechanics, vol. 21, no. 1, Article ID 04020234, 2021.

[3] K. Bian, J. Liu, Z. Liu et al., "Mechanisms of large deformation in soft rock tunnels: a case study of Huangjiazhai Tunnel," Bulletin of Engineering Geology and the Environment, vol. 78, no. 1, pp. 431-444, 2019.

[4] H. Zhang, L. Chen, Y. M. Zhu, Z. L. Zhou, and S. G. Chen, "Stress field distribution and deformation law of large deformation tunnel excavation in soft rock mass," Applied Sciences-Basel, vol. 9, no. 5, 2019.

[5] K. Wu and Z. S. Shao, "Study on the effect of flexible layer on support structures of tunnel excavated in viscoelastic rocks," Journal of Engineering Mechanics, vol. 145, no. 10, Article ID 04019077, 2019.

[6] K. Wu, Z. S. Shao, S. Qin, and B. X. Li, "Determination of deformation mechanism and countermeasures in silty clay tunnel," Journal of Performance of Constructed Facilities, vol. 34, no. 1, Article ID 04019095, 2020.

[7] J. Z. Xiao, F. C. Dai, Y. Q. Wei, and Y. C. Xing, "Comparative analysis of excavation schemes for a tunnel constructed through loose deposits," Journal of Performance of Constructed Facilities, vol. 30, no. 4, Article ID 04015061, 2016.

[8] C. Kong, X. Q. Gao, L. Cao, and K. Liu, "Analysis of the failure of primary support of a deep-buried railway tunnel in silty clay," Engineering Failure Analysis, vol. 66, pp. 259-273, 2016.

[9] G. W. Xu, C. He, J. Yan, and G. Y. Ma, "A new transversely isotropic nonlinear creep model for layered phyllite and its application," Bulletin of Engineering Geology and the Environment, vol. 78, no. 7, pp. 5387-5408, 2019.

[10] T. B. Zhao, Y. B. Zhang, Q. Q. Zhang, and Y. L. Tan, “Analysis on the creep response of bolted rock using bolted burgers model," Geomechanics and Engineering, vol. 14, no. 2, pp. 141-149, 2018.

[11] N. N. Zhang, Q. Fang, Y. Li, and D. L. Zhang, "Mechanical analysis of secondary lining of high-speed railway tunnel," KSCE Journal of Civil Engineering, vol. 22, no. 7, pp. 2384-2389, 2018.

[12] E. Yalcin, Z. Gurocak, R. Ghabchi, and M. Zaman, "Numerical analysis for a realistic support design: case study of the komurhan tunnel in eastern Turkey," International Journal of Geomechanics, vol. 16, no. 3, Article ID 05015001, 2016.

[13] Z. P. Song, T. T. Yang, A. N. Jiang, D. F. Zhang, and Z. B. Jiang, "Experimental investigation and numerical simulation of surrounding rock creep for deep mining tunnels," Journal of the South African Institute of Mining and Metallurgy, vol. 116, no. 12, pp. 1181-1188, 2016.

[14] G. W. Xu, C. He, Z. Q. Chen, and Q. H. Yang, "Transversely isotropic creep behavior of phyllite and its influence on the long-term safety of the secondary lining of tunnels," Engineering Geology, vol. 278, Article ID 105834, 2020.

[15] M. Huang, J. W. Zhan, C. S. Xu, and S. Jiang, "New creep constitutive model for soft rocks and its application in the prediction of time-dependent deformation in tunnels," International Journal of Geomechanics, vol. 20, no. 7, Article ID 04020096, 2020.
[16] K. Wu, Z. S. Shao, S. Qin, and N. N. Zhao, "Analytical-based assessment of effect of highly deformable elements on tunnel lining within viscoelastic rocks," International Journal of Applied Mechanics, vol. 12, no. 3, Article ID 2050030, 2020.

[17] C. Paraskevopoulou and M. Diederichs, "Analysis of timedependent deformation in tunnels using the convergenceconfinement method," Tunnelling and Underground Space Technology, vol. 71, pp. 62-80, 2018.

[18] G. W. Xu, C. He, Q. H. Yang, and B. Wang, "Progressive failure process of secondary lining of a tunnel under creep effect of surrounding rock," Tunnelling and Underground Space Technology, vol. 90, pp. 76-98, 2019.

[19] Z. C. Guan, Y. J. Jiang, Y. Tanabashi, and H. W. Huang, "A new rheological model and its application in mountain tunnelling," Tunnelling and Underground Space Technology, vol. 23, no. 3, pp. 292-299, 2008.

[20] H. Wang, W. Z. Chen, Q. B. Wang, and P. Q. Zheng, "Rheological properties of surrounding rock in deep hard rock tunnels and its reasonable support form," Journal of Central South University, vol. 23, no. 4, pp. 898-905, 2016.

[21] Z. F. Chu, Z. J. Wu, Q. S. Liu, and B. G. Liu, "Analytical solutions for deep-buried lined tunnels considering longitudinal discontinuous excavation in rheological rock mass," Journal of Engineering Mechanics, vol. 146, no. 6, Article ID 04020047, 2020.

[22] Y. C. Wang, Y. Q. Shang, H. Y. Sun, H. Q. Li, and X. H. Xu, "Study on mechanical rules of double-lining in creeping surrounding rock," Hydrogeology \& Engineering Geology, vol. 37, no. 2, pp. 49-54, 2010, in Chinese.

[23] N. Cristescu, D. Fota, and E. Medves, "Tunnel support analysis incorporating rock creep," International Journal of Rock Mechanics and Mining Science \& Geomechanics Abstracts, vol. 24, no. 6, pp. 321-330, 1987.

[24] G. S. Zhao, M. H. Ren, X. H. Qiu, and Q. H. Xue, "The unified strength theory for plastic limit load analysis of vertical shaft lining," Advances in Civil Engineering, vol. 2018, Article ID 1949324, 6 pages, 2018.

[25] W. X. Zheng, Q. W. Bu, and Y. Q. Hu, "Plastic failure analysis of roadway floor surrounding rocks based on unified strength theory," Advances in Civil Engineering, vol. 2018, Article ID 7475698, 10 pages, 2018.

[26] J. Wang, J. H. Zhao, Y. Zhou, and S. S. Sun, "Boundary effect and dynamic response study for the penetration of rigid projectiles into thick, finite-radius, metallic targets," Shock and Vibration, vol. 2020, Article ID 8832925, 16 pages, 2020.

[27] J. Wang, J. H. Zhao, J. H. Zhang, and Y. Zhou, "Study on model of penetration into thick metallic targets with finite planar sizes by long rods," Shock and Vibration, vol. 2021, Article ID 6666770, 9 pages, 2021.

[28] A. R. Kargar and H. Haghgouei, "An analytical solution for time-dependent stress field of lined circular tunnels using complex potential functions in a stepwise procedure," Applied Mathematical Modelling, vol. 77, pp. 1625-1642, 2020.

[29] L. J. Wang and L. H. Wang, "Semianalytical analysis of creep and thermal consolidation behaviors in layered saturated clays," International Journal of Geomechanics, vol. 20, no. 4, Article ID 06020001, 2020.

[30] H. Zhang, H. B. Zhao, X. Y. Zhang et al., "Creep characteristics and model of key unit rock in slope potential slip surface," International Journal of Geomechanics, vol. 19, no. 8, Article ID 04019094, 2019.

[31] J. Yu, G. Y. Liu, and Y. Y. Cai, “Time-dependent deformation mechanism for swelling soft-rock tunnels in coal mines and its mathematical deduction," International Journal of Geomechanics, vol. 20, no. 3, Article ID 04019186, 2020. 
[32] Y. X. Peng, L. Wu, H. H. Peng, Y. Hao, and Y. L. An, "Theoretical and experimental study on rock resistance coefficient of soft rock tunnel considering creep effect," Arabian Journal for Science and Engineering, vol. 45, no. 5, pp. 4333-4342, 2020.

[33] L. Cui, J. J. Zheng, Q. Sheng, and Y. Pan, "A simplified procedure for the interaction between fully-grouted bolts and rock mass for circular tunnels," Computers and Geotechnics, vol. 106, pp. 177-192, 2019.

[34] A. R. Kargar, "An analytical solution for circular tunnels excavated in rock masses exhibiting viscous elastic-plastic behavior," International Journal of Rock Mechanics and Mining Sciences, vol. 124, Article ID 104128, 2019.

[35] A. R. Kargar, H. Haghgouei, and N. Babanouri, "Time-dependent analysis of stress components around lined tunnels with circular configuration considering tunnel advancing rate effects," International Journal of Rock Mechanics and Mining Sciences, vol. 133, Article ID 104422, 2020.

[36] G. Peng, Z. Q. Chen, and J. R. Chen, "Research on rock creep characteristics based on the fractional calculus meshless method," Advances in Civil Engineering, vol. 2018, Article ID 1472840, 6 pages, 2018.

[37] L. M. Yang, J. H. Luo, W. Y. Chen, and Y. M. Mou, “Amplification of seismic response in poroviscoelastic soil layer," Advances in Civil Engineering, vol. 2020, Article ID 8824445, 12 pages, 2020.

[38] J. T. Guo, Z. M. Zhang, Y. L. Tang, and J. Ji, “A simplified viscoelastic solution of the frost heaving force of cavity water behind tunnel linings," Advances in Civil Engineering, vol. 2020, Article ID 8857580, 8 pages, 2020.

[39] Z. F. Chu, Z. J. Wu, B. G. Liu, and Q. S. Liu, "Coupled analytical solutions for deep-buried circular lined tunnels considering tunnel face advancement and soft rock rheology effects," Tunnelling and Underground Space Technology, vol. 94, Article ID 103111, 2019.

[40] Q. Zhang, C. H. Zhang, B. S. Jiang, N. Li, and Y. C. Wang, "Elastoplastic coupling solution of circular openings in strainsoftening rock mass considering pressure-dependent effect," International Journal of Geomechanics, vol. 18, no. 1, Article ID 04017132, 2018

[41] W. S. Zhao, W. Z. Chen, and D. S. Yang, "Effect of an imperfect interface on seismic response of a composite lining tunnel subjected to SH-waves," International Journal of Geomechanics, vol. 18, no. 12, Article ID 04018177, 2018.

[42] Z. Q. Zhang, M. M. He, F. F. Chen, and N. Li, "Excavation sequence and surrounding rock mass stability of large-scale underground engineering with 8 tunnels," Advances in Civil Engineering, vol. 2020, Article ID 3207072, 11 pages, 2020.

[43] Q. Yan, S. C. Li, C. Xie, and Y. Li, "Analytical solution for bolted tunnels in expansive loess using the convergenceconfinement method," International Journal of Geomechanics, vol. 18, no. 1, Article ID 04017124, 2018.

[44] W. J. Yu, K. Li, Z. Liu, B. F. An, P. Wang, and W. Hai, "Mechanical characteristics and deformation control of surrounding rock in weakly cemented siltstone," Environmental Earth Sciences, vol. 80, no. 9, pp. 1-15, 2021.

[45] W. J. Yu and k. Li, "Deformation mechanism and control technology of surrounding rock in the deep-buried large-span chamber," Geofluids, vol. 2020, no. 5, 22 pages, Article ID 8881319, 2020.

[46] J. Zhou, X. A. Yang, M. J. Ma, and L. H. Li, "The support load analysis of deep-buried composite lining tunnel in rheological rock mass," Computers and Geotechnics, vol. 130, Article ID 103934, 2021. 